\title{
Fracasso escolar e condições de vida em crianças de sete a dez anos de idade, Sobral, Ceará
}

Failure at school and the conditions of the lives of children from seven to ten years, in Sobral, Ceará

O objetivo desta pesquisa foi estudar as condições de vida e saúde das crianças de sete a dez anos de idade da zona urbana do município de Sobral e suas relações com o desempenho escolar.

Tratou-se de um estudo epidemiológico de corte transversal, com entrevistas domiciliares, avaliação antropométrica $e$ avaliação laboratorial. O banco de dados foi obtido a partir de uma pesquisa maior com 3444 crianças de cinco a nove anos, sorteadas aleatoriamente a partir do cadastro do Programa de Saúde da Família do município. A amostra desse estudo foi constituída de crianças que tinham sete a dez anos no dia da entrevista domiciliar. De acordo com o desempenho escolar anterior, as crianças foram divididas em três grupos. No grupo A, as crianças que estavam na escola e nunca repetiram, no $B$ as que estavam na escola, mas já haviam repetido e no $C$, as que estavam foram da escola. Foram analisadas as associações entre as variáveis demográficas, sócio-econômicas, ambientais, trabalho infantil, morbidade e consumo de serviços de saúde.

Inicialmente, foram descritas as características para os três grupos. Como os valores para o grupo $\mathrm{C}$ foram muito piores do que os outros dois, foi feita análise univariada somente com os grupos de crianças repetentes $e$ as não repetentes. $\mathrm{Na}$ análise multivariada permaneceram como fatores associados à repetência as variáveis consideradas marcadores sócio-econômicos, renda per capita e escolaridade materna; duas variáveis relacionadas à escolaridade, ajuda para fazer lição e irmão repetente, além das variáveis ser cadastrado no PSF e ter outra religião diferente da católica. Ter um irmão repetente aumentaria o risco de repetência uma vez que estão dadas todas as condições para que outras crianças da família sejam também repetentes. Ter ajuda para fazer lição seria um fator de risco, ao estar selecionando um grupo de crianças que necessitam de ajuda, por apresentarem maior risco de serem reprovadas. A variável cadastro no PSF comportou-se como marcador econômico e a variável ter outra religião pode estar identificando grupos com características próprias favoráveis ao desempenho escolar. Em relação às variáveis de saúde, apenas a referência à desnutrição anterior $e$ a internação foram significativas na análise univariada. Entretanto, essa -associação não se manteve na análise multivariada. Nenhuma das variáveis relacionadas à saúde permaneceu significativa na análise multivariada, o que permite afirmar que, para esse grupo, as condições de saúde não têm relação com o desempenho escolar. Vale destacar que a desnutrição pregressa não diferenciou o grupo de repetentes do de não repetentes.

O estudo permitiu o aprofundamento da compreensão do fracasso escolar, com a inclusão de dimensões importantes para a

* sua rede complexa de causalidade, destacando a importância das condições sócio-econômicas, que se traduzem, nas conjunturas específicas, por variáveis distais especificadas, recomendando a necessidade de estudos sempre apoiados nos contextos específicos.

$$
\begin{array}{r}
\text { Ana Cecília Sucupira } \\
\text { Tese de Doutorado, } 2003 \\
\text { Faculdade de Medicina da Universidade de São } \\
\text { Paulo, São Paulo. } \\
\text { <asucupira@yahoo.com> }
\end{array}
$$

PALAVRAS-CHAVE: Condições de vida; condições de saúde; baixo rendimento escolar; zonas urbanas. KEY WORDS: Living condition; health conditions; underachievement; urban zones.

PALABRAS CLAVE: Condiciones de vida; condiciones de salud; rendimiento escolar bajo; zonas urbanas.

Recebido para publicação em 15/07/04 Aprovado para publicação em 23/07/04. 